\title{
Performative Compliance and the State-Corporate Structuring of Neglect in a Residential Care Home for Older People
}

\author{
Joe Greener ${ }^{1}$ (D) \\ Published online: 13 November 2019 \\ (C) The Author(s) 2019
}

\begin{abstract}
The abuse and neglect of older people in care homes is widespread across England, but current causative explanations are limited and frequently fail to highlight the economic and political factors underpinning poor care. Informed by social harm and state-corporate crime perspectives, this study uses ethnographic data gathered through a nine-month period of working in an older person's residential care home to show how neglect is embedded in working routines. Three aspects of care are interrogated to reveal the embedded nature of harm in the home; all reveal the rift between official, regulatory rules and informal working practices shaped by material constraints of the labor process. This article explores the role of regulatory regimes in actively legitimizing sectors, such as the residential care industry, even in the face of routine violence, by bureaucratically ensuring the appearance of compliance with formal rules. While the harms of contemporary institutionalized care for older people have its roots in material conditions, performative compliance through regulation guarantees that these injurious outcomes are concealed. This article contends that malpractice (and harm) can be explained with reference to conjoint state-corporate relationships and practices.
\end{abstract}

\section{Introduction}

While concerns about the quality of adult social care in England are raised frequently, this often occurs only in light of serious instances of care failings reported in the media (Flynn and Citarella 2013; Sussex County Council 2014). Such occurrences are usually portrayed as anomalous cases — or what Whyte (2014: 241) calls "moments of rupture"-with abuse or severe neglect constructed as particular wrongful events and with the finger of blame pointed at temporary regulatory failure, inept managers or even "evil" care workers. At best, and as Ferguson and Lavalette (2013) point out, the "crisis" in adult social care is due to an aging population or unaffordable welfare budgets, rather than decades of marketization and privatization policies. Current academic research on the matter tends to look

Joe Greener

j.greener@liverpool.ac.uk

1 Department of Sociology, Social Policy and Criminology, University of Liverpool,

Liverpool L69 3BX, UK 
more at organizational contexts without considering political economy, citing factors such as poor "leadership" or inadequate "staff training" (Furness 2006; Marsland et al. 2015), or focusing on micro-interactional phenomena, such as agism or risk factors relating to victims and perpetrators (Stevens et al. 2013).

Using a workplace-based participant methodology, where I assumed the role of a care assistant, this article offers what might be described as ethnography of state-corporate crime and challenges some of the conventional explanations of failing care. It focuses on the pressures and constraints that frontline workers face in attempting to meet the needs of older people and explores some of the resulting routinized harms. This article finds that regulation largely fails to ensure appropriate standards of care and that the actions on-thefloor contravene officially endorsed caring processes.

In this article, the connections between the criminogenic practices exposed are explained with reference to a particular manner in which capital accumulation is instituted in the care sector. I attempt to go beyond both conventional state-corporate crime approaches and the policy-focused care literature in order to offer a deeper analysis of "crimes of the powerful" through an exploration of the political and economic foundations of harm within care facilities (Whyte 2014). The analysis seeks to locate an explanation for the revealed neglect with reference to "symbiotic" and interdependent relationships between state-based regulatory authorities and large corporate service providers (Tombs 2012). The data presented suggest that neglect might be understood with reference to, on the one hand, underfunding in the welfare system as the state seeks to constrain costs of social reproduction, particularly for non-laboring populations, coupled with the desire by successive governments to provide a platform for profit-generation to large multinational capital. As a result of these conditions of capital accumulation, regulation is not driven by an identifiable effort to actually scrutinize caring but might instead be termed performative compliance, where different organizational forces seek to give the illusion that they are conforming to the "agreed" rules of delivery. As this article demonstrates, this performative compliance, coupled with sector-wide underfunding, helps to structure a range of routine forms of care violence, where even basic needs of residents are not secured. In essence, this article demonstrates that the particular institutionalization of accumulation prevalent in the residential sector for older individuals has resulted in severe harm and neglect for many residents.

\section{Theoretical Framework: State-Corporate Symbiosis and Social Harm}

Earlier theories of state-corporate harm focused on instances where governmental and business actors, in cooperation, generate outcomes that result in fatalities, deteriorating well-being or other deleterious effects (e.g., Kramer et al. 2002). Conventionally, these harms have been understood as either "state-initiated" or "state-facilitated" (Kramer et al. 2002: 271-272). The former refers to situations where a state directly employs or commissions corporations to engage in harmful practices, such as the employment of private militias to engage in war crimes. The latter represents cases where the state, especially through inactivity, fails to hold corporations accountable for wrongdoing-often due to mutually held objectives. Harms resulting from a lack of regulation might be conceptualized through this latter category because such harmful business activities are tolerated due to insufficient intensity of regulatory effort. In a number of publications, however, Tombs and Whyte (e.g., Tombs 2012, 2016; Whyte 2014) have argued that this understanding of statefacilitated crime or harm fails to conceptualize the deep-rooted constitutional, material 
and institutional co-dependencies of "the state" and corporations. Offering a "soft" critique of conventional state-corporate crime studies, Tombs (2012: 174) argues that this area of study has tended to focus on particular relationships between specific organizations (between a regulator and a corporation, for instance) in order to understand how violent aftereffects emerge as particular "events" or "instances" of state-corporate crime. This focus on incidents as emergent from specific organizational relationships elides more profound reflection on how states and corporations dually co-create regimes of accumulation, and how these regimes of accumulation may produce mass injury. So, for example, Tombs and Whyte (2007) and Tombs (2016) have shown convincingly how the regulatory regime in the United Kingdom (UK) in its entirety - and demonstrable across many specific industries (from food catering to construction) — has moved increasingly to a position endorsing pro-economic "progress" and at the expense of (or instead of) actual enforcement.

This body of research casts considerable doubt on traditional conceptions of regulation and even basic conceptions of the relationship between government and business. Rather than conceiving of regulatory authorities as policing markets and profit-making entities, or even conceptualizing the state as inherently oppositional or distinct from business, it makes sense to see states (and governmental organizations) as co-determining the ideological, institutional, legal, and social context for accumulation. Indeed, corporations rely on the state to sustain conditions favorable to and essential for the continued existence of corporate activities (Tombs and Whyte 2015). Privatization policies, legal/policy frameworks establishing labor conditions, direct payments through contracts or subsidies, promulgation of a range of narratives, and the maintenance of a holistic socio-legal order are all state activities that create the institutional and ideological platform for corporate accumulation. Regulation, despite being constructed within mainstream neoliberal politics as an external anti-business policer of corporations, can be viewed alternatively as a central component of the overall institutional matrix that enables and institutionalizes accumulation. While regulation often provides workers, citizens and the environment some modicum of protection, direct intervention by the state is more often than not an attempt to nullify the most damaging aspects of corporate power (Tombs and Whyte 2010a, b). Within the conception that regulation may actually be conducive with maintaining corporate activity, regulation can be conceived as having two primary purposes. First, it helps to secure the overall social order within which accumulation occurs by containing (some of) the most negative aspects of corporate activity but, second, it also has a more inventive function in that it institutes markets. Accordingly, regulatory agencies "are caught somewhere between the despotic and the infrastructural, the coercive and the creative functions of states" (Whyte 2014: 240).

In order to demonstrate how the particular institutionalization of accumulation in residential care for older people produces harm, this article also develops some insights from social harm theory. The studying of harm is premised on the political assertion that statedefined categories of "crime" are inherently limiting and that a focus on emotional, material, physical, psychological or social damage can overcome moral relativism, refocusing attentions on how capitalism produces maltreatment. This article borrows from expansive and ontological conceptions which generally equate harm with a transgression of some primary or elementary dimension of humanness or being (Garside 2013; Lasslett 2010; Pemberton 2015). Pemberton's (2015: 24) needs-based conception of social harm guides researchers to explore empirically the role of "relations, processes, flows, practices, discourse, actions and inactions" (emphasis in original) in structuring different forms of injury to individuals' corporeal states, psychological conditions, and abilities to achieve self-actualization. 
Before presenting my ethnographic data, this article highlights some of the sectoral conditions shaping the harms discussed later and, in particular, the structural conditions which create models of profit dependent on extreme cost-saving.

\section{Institutionalizing Accumulation in Older People's Residential Care in England}

Since the late 1980s, market competition in social care has developed with the involvement of private, state and charitable contenders in a "mixed" economy (Beresford 2005). Large-scale corporations dominate but are funded largely through local/central government budgets, as payment for care home fees usually derive from a mix of personal finances and state-support. In 2008, $58 \%$ of private homes were owned and operated by large corporate providers in England in a sector where $81 \%$ of establishments are operated for profit (Lewis and West 2014: 2). In other words, money paid directly by the state is perhaps the most dependable and substantial income source for the residential care industry. In 2013-2014, 50\% of residents in private and voluntary sector homes were either wholly or partially funded by local government and a further $7 \%$ are paid for by the National Health Service (NHS) (Grant Thornton 2014: 11). Local authorities-the primary unit of local public service provision in the UK - tend to favor low-cost providers when they are shouldering some or all of the expenses. This tends to constrain fees (Fotaki et al. 2013) with the result that providers have sought a range of identifiable strategies aimed at limiting costs. These include large-scale employment of migrant workers (Cangiano et al. 2009), seeking reductions in production expenses (Collins 2012), and engaging in complex financial restructuring initiatives (Scourfield 2012).

While local and central government funding constrains fees paid to providers, it also appears that considerable effort is devoted to attempting to regulate and standardize care procedures. The Care Quality Commission (CQC) sets the "fundamental standards," which are the benchmark for care in any formal service. These cover areas such as "person-centred care," "food and drink," "staffing" and "premises and equipment." These standardized frameworks for regulating care have been criticized widely. The focus on person-centered care, in particular, is a manifestation of the personalization agenda, where welfare users are imagined as consumers in a market, and quality is imagined as being synonymous with delivering "choice" and "control" (Ferguson 2007). Some argue that policy and provision remains concerned primarily with more biomedical aspects of caring. Lewis and West (2014: 3), for example, argue that the regulatory and policy focus has shifted toward "outcomes and measures," with less attention being paid to rigorous inspection procedures, the core care relationship, or the capacity of organizations to enable socially beneficial care environments. Perhaps more importantly, regulation appears to have failed to secure a basic level of quality in service delivery with widespread reports from across England and the UK of understaffing across organizations.

The exact manner in which capital accumulation has been instituted within the residential care for older people sector has led to a series of systemic problems of funding. Available evidence would also seem to suggest that regulatory efforts have failed to secure quality care across the sector (Moore 2018). The findings of this study unpack the dynamics within one care home to reveal how the specific institutionalization of accumulation within the sector compels a rationalizing of the costs of production, seeking savings in all aspects of service design, while government regulation fails in securing quality services, arguably because it is more concerned with endorsing the sector than actually policing it. 


\section{Methods and Ethnographic Setting}

This ethnographic study attempts to understand the competing pressures that influence care with reference to the actors involved, descriptions of tasks, events, language, organizational goals, uses (and abuses) of technology, and spatial arrangements (Rees and Gatenby 2014: 14-15). Analysis goes beyond the discursive dimensions of life in the home and attempts to explain and document more material and embodied aspects, such as tendencies in working patterns and resulting relationships between actors. Data were collected during nine months of participant ethnography during which I assumed employment as a care assistant. Between two and four 12-hour shifts were undertaken each week. Between 25 and 35 residents inhabited the home but numbers changed relatively rapidly as people came and went for respite, were admitted to hospital, or died. Residents suffered, to varying degrees, from a complex combination of emotional, physical and psychological problems, and the vast majority had received a diagnosis of dementia.

Data collection and analysis involved collecting and developing detailed research notes. Thorough descriptions of conversations and events were recorded in the hours and days after each shift. Recording events and dialogs accurately was the utmost concern. Descriptive notes were supplemented with theoretical, reflective and conceptual expansionssometimes referred to as "theoretical memos" (Montgomery and Bailey 2007: 65). In ethnographic research, there are well-recognized problems with recording precise and exact descriptions of events (LeCompte and Goetz 1982). For instance, when participating in social events, ethnographers may be able to make only "headnotes," requiring them to write up the events in more detail at a later moment (Emerson et al. 1995). Thus, I cannot claim that the statements that appear in the following sections reflect word-for-word what was said, but they are representations of my memories of events and discussions. The data presented are an attempt to represent the overall organization of work and the difficultiesfacing workers as they struggle to ensure the well-being of residents. Vignettes in the form of quotations are employed to provide a sense of the people and the problems faced.

The project was subject to extensive ethical review from both an institutional review panel and the head of my university's law school. The study involved some practices that are considered ethically sensitive by prevailing standards. Informed consent was not gathered from some participants in the social context, including residents and family members. Throughout various forms of ethical examination, some degree of non-disclosure was supported by those reviewing the study. The panel stated that it supported the research project because care homes were known sites of harmful outcomes, funded largely through public monies, and shielded from scrutiny by corporate actors. Alvesalo-Kuusi and Whyte's (2018) recent article on redesigning ethics for research with powerful or elite groups argues that the permissibility of different strategies should be based on collective or universal interests, rather than professional or institutional priorities. They point toward a "paradox" in conventional ethics, whereby current standards of ethics are designed to address power imbalances between researched and researcher, but the same rules tend to protect the powerful. This project is concerned with how states and corporations engage in organizing harm, and both the researcher and formal ethical procedures decreed that some suspension of conventional customs were justified. Parker and Crabtree (2014: 37), writing specifically on the use of covert methodologies for uncovering abuses within adult social care settings, argue that "covert or semi-covert research, where consent is not always possible, is one way in which we can uncover truths that need to be heard, but may not be heard using conventional methods." 
Specific recommendations emerged from the institutional review process regarding what was permissible conduct for the study. Where possible, I obtained consent informally from workers and care home managers. Regarding initial entry into the home, I obtained consent from the employing manager. Likewise, many of the workers were aware that I was conducting research into care quality and was drawing on experiences of working in the home. So, while the research had a covert element, it did not involve direct deception (Spicker 2011). I made clear that protecting the well-being of the older people was the utmost propriety for my study and, as such, adhered to a number of measures that were suggested to me. All research tasks, such as recording notes and writing up field observations, took place outside of work-time. During shifts, my primary objective was a commitment to care responsibilities and to meeting the needs of residents. Securing the anonymity of all residents and their family members, as well as workers and managers, was paramount (and all names used here are pseudonyms). The location of the home remains secret. As far as possible, the focus was maintained on work practices, organizational issues and shortcomings in care quality.

\section{State-Corporate Structuring of Neglect: Chronic Underfunding}

In this context, two pressures represent the epicenter of state-corporate structuring of neglect: first, work was performed in an under-resourced, low-staffed environment; and second, compliance with regulation occurred only rarely. A range of cost-reduction strategies were employed by the home to maintain low inputs, including depleted personnelto-resident ratios. When care staff were absent due to illness, replacements were sought infrequently. Regularly, residents needed to be accompanied to appointments with general practitioners or to the hospital, requiring one care assistant to be "off the floor" for some hours. Usually, there were between five and seven care workers on shift, but at times, the number fell to three and, on one occasion, only two workers were present. The accepted minimum staffing ratio at the time was 1:5 (workers to residents). Frequently, the home was in breach of this standard.

Managerial objectives aimed at further cost cutting maintained low expenditure throughout the home. The entertainment budget (used for birthdays and other such events) had been withdrawn and a "Caring for Dementia" course, aimed at developing dementia-specific communication and care skills, had also been discontinued. At the time of research, the food budget was under threat, and management proposed a cutback of 10 percent despite the budget being an already meager $£ 2.75$ per resident, per day (see Collins 2012). The combination of low labor inputs and a generalized strategy of cost reduction resulted in care falling short of regulatory expectations. Many of the needs of individual residents were not met, including emotional, social and elementary biological needs.

Care workers and managers often stated strong moral and ethical motivations for meeting the needs of residents. According to Leanne, a senior care assistant, "Not everyone is cut out for this job, not everyone can do this job. You've got to have something about you, a commitment or a calling... You've got to be able to put the needs of the residents first."

Workers often displayed anger or frustration about inadequate staffing. After having worked a particularly challenging shift, Magdalena, a care assistant, complained:

There's never enough people to get through the work. Yesterday me and one other did the whole home right up until tea time [11 am]. Three floors with just the two of 
us...but even when there's more staff it's still not right... We never have time to sit or just watch TV with the residents or do something different.

In one conversation, the home manger at the time complained about her role in maintaining low staffing levels:

I know this [staffing levels] is a problem...I know exactly what you mean, but you've got to realise that at the end of the day this is a business... and to make profit you've got to drive down the costs of running the place... I agree that it might be wrong that this is a business but this is the way it has gone, and with all these old people it is unlikely to change.

On any given day shift, there were three to seven care assistants or senior care assistants, as well as one or two cleaners, two to three kitchen staff, one nurse, one janitor/handyman and one home manager. Care assistants and senior care assistants carried out the vast majority of personal care tasks, while nurses focused on duties requiring medical expertise, such as managing medications. Both nurses and care assistants worked $12 \mathrm{~h}$ shifts, from 8 am until $8 \mathrm{pm}$, or $8 \mathrm{pm}$ to $8 \mathrm{am}$. Care assistants were paid minimum wage (at the time, $£ 5.80$ per hour), and senior care assistants earned $21 \mathrm{p}$ per hour more. The workforce was multinational with staff members having moved from India, Kenya, Latvia, Malawi, Nigeria, Philippines, Poland, Russia, South Africa, Ukraine and Zimbabwe-a reflection of the internationalized nature of the social care workforce in the UK (Cangiano et al. 2009). Precarious situations experienced by migrant workers offered a series of benefits for the employer by reducing turnover rates, providing access to "over-skilled" labor, and compelling workers to remain in unpleasant working conditions and work a greater numbers of hours (Anderson 2010). Those from outside the European Union complained frequently about their visa situation, which tied them to the social care sector or even to employment within the home. Aneni, a care assistant from Zimbabwe, who worked six 12-h shifts most weeks, explained her reasons for continuing to work in social care:

There's no way I can go back to Zimbabwe because of the political situation...I haven't been able to get asylum so I'm on a visa which ties me to working in social care even though in Zimbabwe I was a nurse.

In all aspects of service delivery, including staffing, tertiary costs (such as entertainment), and core costs (such as food), management appeared to be attempting to find areas or ways in which it could reduce costs and sustain minimal spending. There was an all-encompassing strategy to decrease the production costs of delivering care in the home. A private equity firm with financial interests in the residential care market argued in an investors report in 2014 that maintaining low cost across the sector was central to securing profitability. The then-Head of Private Sector Healthcare at the firm noted that, "government austerity, increasing costs and static fees will continue to erode private sector earnings" (Grant Thornton 2014: 5). As the next section demonstrates, the prevailing tendency to seek cost reductions in staffing meant state-authorized forms of care were practiced only rarely in the home, pushing workers to commit fraudulent acts in order to maintain an appearance of quality care for external onlookers. 


\section{State-Corporate Structuring of Neglect: Performative Compliance with Regulation}

As in other studies of care work, practices in the home can be understood as having formal and informal features (Bolton and Wibberley 2014; Lopez 2007). The formal aspects of the work were those written on or into care plans, task sheets and other bureaucratic instruments, which represented the contractual agreements between state and private profit-generating organizations determining requirements about how much and what work should be completed. Two cornerstone bureaucratic apparatuses underpinned the formal dimensions of the work. The care plans, initiated on admittance, recorded the individual's personal emotional, physiological, psychological and cultural requirements and preferences-the organization's statement of intent to provide a certain level of service aligned to external regulation. The care files provided evidence of tasks completed each day. During shifts, care assistants and senior care assistants were required to note each task completed with every resident (such as fluid/food intake and incontinence pad changes). The care files also recorded tasks completed and were aimed at substantiating the home's responsiveness to needs of residents.

Managers reproved workers not on the basis of whether tasks had been completed, but according to whether files reflected regulatory standards. The home managers' mantra was "if it's not written down, it didn't happen," which was also reproduced on a sign above the shelves where the care files were stored (see also Diamond 1992). The home manager (Karen) would frequently express the importance of "correct" record keeping, especially when an external force, such as a resident's relative or an external organization, had submitted complaints:

It's important you write down everything in the care files. And I mean everything. If you don't write down everything how can I protect you? It's like with Brenda's daughter, she's gone to the Council complaining that her mum is losing weight, so if you don't write absolutely everything down I can't prove how much Brenda has eaten.

Aside from care files and care plans, the third formal aspect of care work, although not purely bureaucratic, was the expectation that staff attend externally and internally provided training courses on a range of different aspects of care. Sessions often finished with the signing of forms confirming attendance.

The commitment to delivering state-certified care was symbolic, with little direct supervision; it entailed formal endorsement of certain practices but informal acceptance of alternative working styles. This "mock routinisation," as framed by Lopez (2007: 225), is systematic rule-violation expected of workers and sanctioned unofficially by managers.

Care files and plans were scrutinized externally by state agencies and internally by home and regional level managers. Frontline staff felt pressured to falsify records, especially care files, which tended to be the first documents inspected in the face of complaints. As Beatrice, a care assistant, explained:

Nothing in these records reflects the reality of what happened. We sit down every evening and write down whatever we have to, to keep them off our back [management]... How do I know how many times Betty was turned or how much Jack has eaten? 
Workers were placed in a quagmire: by falsifying records, they were committing a fraudulent act and were participating in serious harm (such as inadequate food or hydration for particular resident; if they did not, they were risking managerial penance.

Toward the end of the data collection period, a formal Care Quality Commission (CQC) inspection took place with the home receiving a 3 star (adequate) rating — an improvement on previous outcomes. The process of inspection involved examination of all documentation and interviews with eight staff and a number of residents. Interviewees, however, had been identified by the home manager. One care assistant, Janine from Kenya, with an immigration status tying her to employment in the care sector, described her experiences in the interview with CQC. Janine was providing financial support to her daughter and her disabled mother, both of whom resided in Kenya. She commented:

As if I would tell them [CQC inspectors] what is really going on here. I told them nothing and I said everything was good here... If I get sacked then I've got one month to find another job or I have to leave the UK. Would they give me a good reference?

Most homes round here are owned by them [this company] anyway.

Processes, tasks and activities on-the-floor were not observed, and managers were given a significant degree of control over access to information.

In actuality, meeting the needs of residents happened outside of formal expectancies and emerged from the competing informal pressures. As already noted, the majority of the staff appeared to have a strong commitment to providing support for residents. Some residents were more capable of asking or demanding care than those with more severe intellectual or cognitive impairments. Workers developed favorites and those whom they disliked, which also shaped the selection and timing of care tasks. Formally sanctioned work processes largely failed. The inadequacy of care arose from both constrained resources and failing regulation and, accordingly, can be described as structured by state policies and corporate objectives. External regulation orientated around the inspection of documentation rather than scrutinizing the health and well-being of residents or any attempt to observe the work. By means of performative compliance and regulation, a degree of credibility or legitimacy was achieved for both corporate involvement in the residential sector and the government's wider funding and marketization policies. The actual everyday practices performing regulation required that care files were completed, care records updated carefully, and training expectations fulfilled. At the same time, intervention by external authorities was insubstantial and focused on a small selection of interviews with staff members, thereby constituting a further example of "regulation without enforcement" (Tombs 2016). Regulation was performative in that it was a means for securing political acceptability for the continuance of, what is arguably, a failing system. In ensuring that all records were complete, the corporation in question appeared compliant.

Through detailed scrutiny of the records, official regulatory authorities enact an image of toughness, conducting independent, impartial and thorough examinations of servicequality. In reality, the very existence of regulatory procedures, accompanied by the formally stated commitment by providers to follow these regulations, helps to provide an overarching legitimacy to the industry. Both seek to appear as though standards are implemented, training regimens adhered to, and careful and accurate record keeping is in place. Arguably, the very existence of this bureaucratic regime establishes a veneer of compliance dissuading other types of scrutiny from, for example, family members. This situation is a further case of a permissive form of regulation, composed through state-corporate relationships (Tombs 2016; Whyte 2014) - although in this case, regulation is geared toward 
legitimizing a sector which may well be deeply harmful. The next section uncovers some of the violent effects within the care home discussed.

\section{Performing Compliance and Harmful Care in Three Dimensions}

The poor quality of care which emerged as a result of the underfunded labor process and the performative compliance with regulatory frameworks had disastrous results for the residents. Three dimensions of care work are discussed here to reveal the harm associated with care-failure to the fore: (1) person-centered care; (2) moving and handling; and (3) feeding and nutrition. Associated with each dimension is also a set of harms. The formally advised methods of working, the actual informal practices and the associated harms for each of the three dimensions of care are mapped out in Table 1. These are not exhaustive, as a whole host of other elements of the care could have been highlighted, such as assistance with incontinence, the control of toxic and dangerous substances, and practices relating to palliative care. The intention in this section is to show how those regulatory or official aspects of care (the formal) are effectively performative because they fail to ensure that care takes place as it supposed to as workers fall into a series of alternative informaland harmful- practices.

A skeptical, but not wholly dismissive stance is assumed toward the recommendations of regulation (Timmersmans and Almeling 2009). Compliance and fulfillment of approved standards would have seen an identifiable improvement in services, yet would likely have still sidelined the care relationship in favor of physiological needs.

\section{Person-centered care}

Person-centered care decrees that providers must take action to ensure that care "is based on an assessment of [service users] needs and preferences" (CQC 2018a, b, c). In addition, users of care must be supported to make informed choices. The company in question adopted and reproduced the discursive construction that their care was defined by individual choice and control. This quotation is from the 2009 financial annual report:

Our aim is to make it a home from home. That is what our concept of personalised care is all about-making sure that our residents can carry on normal life as far as possible just as if they were still living in their homes. That means treating everyone for who they are-individuals - with rights to privacy, dignity and choice in all aspects of their lives.

In one training session, entitled "Dignity in Care," conducted by a regional manager, the importance of delivering choice in all aspects of the service was communicated to care and kitchen workers. Clothing, daily routines, food and drink preferences, and leisure pursuits were all identified as areas of life where users should exercise decision making. The role of staff in this vision of care was to make these choices a reality. Shirleen, a regional manager, stated:

How many times have you just poured a resident a drink without offering them a choice? How many times have you picked a resident's outfit for the day without consulting them?... That's we we're trying to achieve here. Residents should be able to choose what they do day to day. 


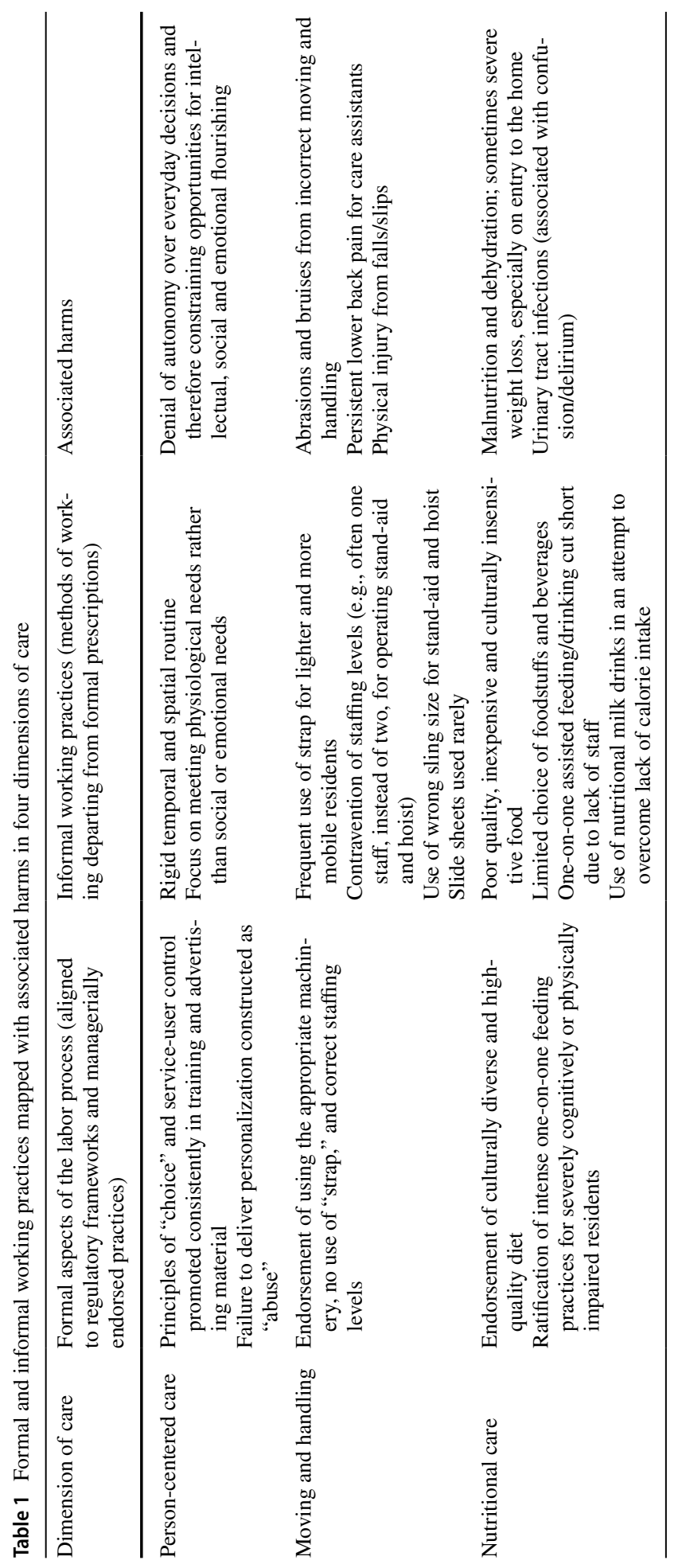


Through the 2-hour session, failure to deliver personalized care was equated with abuse. As one care assistant (Bethany) said shortly after the training course, many felt that delivering the sanctioned person-centered care was difficult if not impossible:

Yeah but we abuse people all the time...They've said to us that this is abuse [not delivering personalised care], whenever somebody says they don't want to do something and we say they have to, that's abuse... Or whenever we say "right come on you it's time to do this." It's all abuse.

The rigid and routinized schedule was one of the key components of the organization of the work which ensured a minimal level of care. The need to maintain the routine often competed with an employee's ability to assist residents in personal decisions. Residents would sometimes challenge the routine in order to better suit their desires or preferences. One resident, Jane, who no longer wished to spend her days in the lounge area, asked to be left in her own room. The manager, against the workers' wishes, accepted her bidding and, for around two weeks, Jane was permitted to stay in her own room. Jane liked staff to spend one-on-one time with her in room and frequently rang the buzzer in order to ask for refreshments. Demands on staff time quickly resulted in her choice being overruled. There was minimal support provided for leisure activities and the rigidity of the daily routine limited engagement with individual residents and made it difficult to support residents' wishes. Workers were very much aware of how the routinized nature of care impacted the ability to be responsive to individual needs. Becky, a senior care assistant, lamented:

In this job there's never any time to spend with anybody [residents]. It's a rush every day. If you get behind in the morning then everything is out of sync for the rest of the day...like sitting and talking to residents is what we should be doing but like any of us have time for that.

The failure of person-centered care has serious implications. Opportunities for forming relationships and shaping the residents' daily lives were severely limited, leaving little scope for the promotion of emotional, intellectual and social flourishing. Practices in the home represented a direct denial of resident's status as social beings (Garside 2013) or what could be described as "autonomy harms" (Pemberton 2015: 29). The style of care limited severely the capacity for self-actualization through social participation and self-determination.

\section{Moving and Handling}

The Health and Safety Executive's (HSE) advice on hoisting equipment describes a number of practices which can compromise safe use (HSE 2011: 1). These include selection of the wrong size of sling, incorrect equipment for the task, and poor maintenance. Much of the moving and handling practices in the home were direct contraventions of formal HSE regulations with improper use revolving around two separate practices: use of inappropriate equipment for resident/task and insufficient number of operators for the equipment.

In order to rationalize efforts given the restrictive staffing levels, workers often utilized inappropriate equipment for the task-at-hand. This is best underlined by the use of a transfer belt that was known colloquially by workers as "the strap." The strap is intended for assisting care recipients with only minor mobility problems very short distances, such as from a wheelchair to a toilet. It affixes round the midriff and contains a series of handles for lifting the person. In moving handling training, imparted by a regional manager, the 
transfer belt was taken from the living room, where it normally stayed, and was used as a prop during the training session. Diane, a regional manager, explained:

This [holds up the transfer belt], should never be used. These are considered completely unsafe now and we should always be using a stand-aid or a hoist. This can be used as extra protection for helping people get up to the stand-aid handles.

At the conclusion of the training, attendees were required to sign sheet indicating that the guidelines were understood. The manager replaced the strap in the lounge area, and Bonnie (a care assistant), while using the strap shortly thereafter, noted the hypocrisy of the situation:

If they don't want us to use the strap why didn't she take it with her? She knows that some of the residents like being lifted this way and she knows it saves us time.

There were a limited number of stand-aids and hoists in the home-bulky pieces of machinery that required properly fitting slings. Using the hoist or the stand-aid was laborious as it required workers to find the devices (which could be anywhere around the home) and then transfer them to the required location. The hoist required attention to ensure that the sling was fitted safely first and both stand-aids and hoists were operated gently. Similar practices were applicable to slide sheets. In order to prevent abrasions, special sheets should be employed when repositioning immobile residents on their bed. These were rarely used, however, as fitting the sheet was time-consuming as compared to lifting.

Using equipment without the prescribed staff levels was common. Correct use of stand-aids and hoists required two operators. HSE (2011: 2)guidance on hoisting states that "two handlers are required: one to operate the hoist; the other to help steady things and, where needed, support the person's lower legs to keep them in a safe position when moving from one place to another." This guideline of two-to-one, while using the heavier lifting machinery, was often ignored as workers sought to perform tasks under pressure.

These contraventions of guidelines were (and continue to be) harmful for both workers and residents. Persistent back pain and musculoskeletal disorders have been associated with nursing and care work (Yassi and Lockhart 2013). The HSE (2011) notes that its guidelines on safe moving and handling are intended to prevent musculoskeletal disorders for workers and the injury or even death of care recipients. Many workers in this site complained frequently about persistent pain.

It was perilous for the resident every time he/she was lifted with an inappropriate piece of equipment or minimum operator protocols were violated (HSE 2011). And, as noted above, serious injuries and deaths have been documented as a result of inappropriate usage of moving and handling equipment.

\section{Nutritional care}

The third dimension is the inadequate provision of residents' nutritional needs. Nutritional care, for it to be aligned with regulatory prescriptions, should produce healthy and tasty nourishment, while ensuring support and assistance for feeding. The CQC (2018c) stipulates that care providers must ensure hydration and nutrition are adequate to "sustain life and good health." 
At the facility where I conducted this study, hydration and nutrition were not recorded accurately as workers usually noted just the recommended number. For example, 1500 milliliters in fluid intake (the recommended daily amount) was documented for every resident, even if staff were unsure of how much an individual had imbibed. For the most infirm, it could take as long an hour to finish a meal even with considerable assistance. Workers compensated for this by giving residents high-calorie drinks to complement their diets. The quality, diversity and cultural sensitivity of the food available were also substandard.

A range of physical harms were associated with the poor nutritional care. These included high instances of urinary tract infections, which is associated with mild dehydration (Beetz 2003), and heightened confusion and delirium (Balogun and Philbrick 2014), as well as weight loss, especially in the early stages of admittance.

\section{Discussion}

While some previous studies have suggested that informal modes of delivering care are essential, as human needs are unpredictable and not easily subsumed into bureaucratic forms of planning (Lopez 2007), this study has shown that informal modes of working may have a more sinister side. These harms emerged from the inability of staff and management to implement forms of care in accordance with regulatory visions of quality and wider company-stated intentions. The failure to meet basic physical and social needs for residents in this private-sector care home emerged at the intersection of state policies and corporate objectives - a form of state-corporate harm structured through a political economy of privatization and an accompanying facade of tokenistic regulation. While this study is limited by its focus on only one care home, there is evidence that residential care for older people and adult social care, more generally, are shaped by deep-rooted macro-structural contradictions. The harms described are social in nature because they are not the result of poor training, bad management or some technical problem with work organization per se, but arise from the political and economic forces shaping care. The dynamics described in this article reveal that the formal aspects of caring - those enacted by regulatory authoritiesare superseded by material conditions, which can lead standards to be enacted discursively but practically inactivated.

These contradictions-between state expectations and material conditions of carearise at the juncture between profit motives and wider neoliberal welfare state priorities. The harm embedded in the residential care market can be seen as state-initiated and facilitated (Kramer et al. 2002). The case discussed here, however, is better understood with reference to wider institutional processes and a deeper analysis of the role of regulation in the care sector. The state "has a clear role in creating and maintaining" all markets (Tombs and Whyte 2015: 23), and this is true in social care. The destruction of state-led social care and the simultaneous creation of a market, originally through NHS and the Community Care Act of 1990, has resulted in widespread privatization and corporate involvement, coupled with continued funding difficulties. By setting the rates of funding, the state has constrained the quality of care, restricting the amount of resources at the hands of the providers. Given the structural formation of the market, cost reduction has emerged as a central strategy for achieving profitability. Any reduction in costs, such as limiting staffing levels or reducing production expenses, has tended to increase the margin between funding collected and money "left over" - or profit. Both factors impart structural pressures toward continual 
rationalizing of staffing and other costs in the labor process. The surrounding market conditions (profit motives and funding arrangements) create an entrenched propensity for firms to follow strategies which have damaging effects for workers and residents. This structural preconditioning toward limiting costs shapes other strategies, such as a reliance on immigrant labor, as a source of a cheap, highly exploitable work force (Anderson 2010). As the residential care market has matured, large multinational corporations have obtained a larger market share. These providers have a number of benefits at their hand: they are able to seek cost-savings through economies of scale; they have eliminated competition by instigating local or regional strongholds; and they are able to more effectively lobby the government for beneficial policies, such as applying pressure for increasing fee rates (Scourfield 2007, 2012). In essence, state funding falls below what would be necessary to begin to build the sorts of care environments, across the whole of society, that are conducive with promoting well-being. Corporate involvement, however and profit motives, more generally, from the evidence uncovered here, can be seen to compound problems with funding because providers are attempting to extract profits from already meager funds.

Regulation serves a particular role in the institutionalization of this market and in facilitating the accumulation of corporations. Regulatory efforts-such as inspections, commitments to standards of care or training requirements - can be seen as legitimacy-seeking exercises. In this case of social care for older people, regulatory efforts fall considerably short of even representing real attempts to secure or deliver quality, which is not surprising considering the welfare funding that might be required to ensure care in practice. What is uncovered in this study is that compliance with various standards becomes feigned by the corporation just as policing is performed by the so-called independent regulators.

Theories of regulation tend to see the state as antagonistically opposed to-or at least somehow separate from-big business. On the contrary, regulatory efforts attempt to reproduce existing conditions rather than representing a tangible attempt to exert control over businesses (Tombs and Whyte 2010a, b). In the case of social care, it may be that the primary intention of regulation is to give credence to the overall system and the accumulation of private enterprises that takes place by establishing the appearance of regulatory effort coupled with an illusion of corporate compliance. This relationship produces and masks harm, establishes an institutional environment where a market for social care is reproduced continually, and, lastly, protects the sector from more serious and intence political scrutiny. Rather than containing the worst aspects of corporate activity in this sector, regulation may serve to obscure what might be widespread routine forms of injurious activity through a veil of bureaucratic compliance.

\section{Conclusion}

The focus on the state-corporate relationship is a relevant starting place for understanding neglect and mistreatment in many care homes and other welfare facilities under contemporary neoliberalized public services. Both social harm and state-corporate crime perspectives offer powerful critical lenses for improving our understanding of the interplay between state practices and corporate agendas in the production of deleterious consequences inside welfare services. Given the range and extent of corporate involvement in welfare services, these perspectives offer useful tools for explaining harm and violence in other areas of social policy. 
As a final comment, the performative compliance that was uncovered in this case study does seem to give justification for state-corporate crime scholars to continue to develop and engage with alternative and non-conventional research strategies. Had a more traditional interview-based strategy been followed in this instance, it is unlikely that the extent of the neglect or the underlying causative mechanisms would have been uncovered.

Acknowledgements The author expresses thanks to Christian Perrin and Pablo Ciocchini who provided constructive comments on earlier drafts of this article. Appreciation is also expressed to Julia O'Connell Davidson who guided the author through the period of data collection. Finally, the careful and considered suggestions offered by the anonymous reviewers were central to developing the arguments presented here.

Funding This study was funded by University of Nottingham. In order to protect the anonymity of the care home at the center of this study, however, ethical review indicated that the funder should remain a secret.

\section{Compliance with Ethical Standards}

Conflict of interest There is no conflict of interest arising from the study.

Ethical Standard The study is fully compliant with the ethical standards set by the University of Nottingham institutional review panel. The research has gone through considerable ethical review at the institutional level. More details are provided in the paper concerning both the ethical rationalization and research design.

Open Access This article is distributed under the terms of the Creative Commons Attribution 4.0 International License (http://creativecommons.org/licenses/by/4.0/), which permits unrestricted use, distribution, and reproduction in any medium, provided you give appropriate credit to the original author(s) and the source, provide a link to the Creative Commons license, and indicate if changes were made.

\section{References}

Alvesalo-Kuusi, A., \& Whyte, D. (2018). Researching the powerful: A call for the reconstruction of research ethics. Sociological Research Online, 23(1), 136-152.

Anderson, B. (2010). Migration, immigration controls and the fashioning of precarious workers. Work, Employment \& Society, 24(2), 300-317.

Balogun, S. A., \& Philbrick, J. T. (2014). Delirium, a symptom of UTI in the elderly: Fact or fable? A systematic review. Canadian Geriatrics Journal, 17(1), 22-26.

Beetz, R. (2003). Mild dehydration: A risk factor of urinary tract infection? European Journal of Clinical Nutrition, 47(2), 52-58.

Beresford, P. (2005). Redistributing profit and loss: The new economics of the market and welfare. Critical Social Policy, 25(4), 464-482.

Bolton, S. C., \& Wibberley, G. (2014). Domiciliary care: The formal and informal labour process. Sociology, 48(4), 682-697.

Cangiano, A., Shutes, I., Spencer, S., \& Leeson, G. (2009). Migrant care workers in ageing societies: Research findings in the United Kingdom. Oxford: COMPAS Report.

Care Quality Commission. (2018a). The fundamental standards. Accessed June 28, 2018, from https://www. cqc.org.uk/what-we-do/how-we-do-our-job/fundamental-standards.

Care Quality Commission. (2018b). Regulation 9: Person-centred care. Accessed June 28, 2018, from https ://www.cqc.org.uk/guidance-providers/regulations-enforcement/regulation-9-person-centred-care.

Care Quality Commission. (2018c). Regulation 14: Meeting nutritional and hydration needs. Accessed June 28, 2018, from http://www.cqc.org.uk/guidance-providers/regulations-enforcement/regulation-14meeting-nutritional-hydration-needs\#guidance.

Collins, N. (2012). Care home residents fed on $£ 2.27$ a day. The Telegraph. Accessed September 30, 2019, from https://www.telegraph.co.uk/news/health/elder/9077377/Care-home-residents-fed-on-2.27-a-day. html. 
Diamond, T. (1992). Making grey gold: Narrative of nursing home care. Chicago: University of Chicago Press.

Emerson, R. M., Fretz, R. I., \& Shaw, L. L. (1995). Writing ethnographic fieldnotes. Chicago: University of Chicago Press.

Ferguson, I. (2007). Increasing user choice or privatizing risk? The antinomies of personalization. British Journal of Social Work, 37(1), 387-403.

Ferguson, I., \& Lavalette, M. (2013). Crisis in adult social care. Bristol: Policy Press.

Flynn, M., \& Citarella, V. (2013). Winterbourne view hospital; A glimpse of the legacy. The Journal of Adult Protection, 15(4), 173-181.

Fotaki, M., Ruane, S., \& Leys, C. (2013). The future of the NHS? Lessons from the market in social care in England. London: CHPI.

Furness, S. (2006). Recognising and addressing elder abuse in care homes: Views from residents and managers. The Journal of Adult Protection, 8(1), 33-49.

Garside, R. (2013). Addressing social harm: Better regulation versus social transformation. Revista Crítica Penal y Poder, 5, 247-265.

Grant Thornton. (2014). Residential elderly care: UK sector review. Accessed September 30, 2019, from https://www.grantthornton.co.uk/insights/private-residential-elderly-care-uk-sector-review/.

Health and Safety Executive. (2011). Getting to grips with hoisting people. London: HSE.

Kramer, R. C., Michalowski, R. J., \& Kauzlarich, D. (2002). The origins and development of the concept and theory of state-corporate crime. Crime \& Delinquency, 48(2), 263-282.

Lasslett, K. (2010). Crime or social harm? A dialectical perspective. Crime, Law \& Social Change, 54(1), $1-19$.

LeCompte, M. D., \& Goetz, J. P. (1982). Problems of reliability and validity in ethnographic research. Review of Educational Research, 52(1), 31-60.

Lewis, J., \& West, A. (2014). Re-shaping social care services for older people in England: Policy development and the problem of achieving good care. Journal of Social Policy, 43(1), 1-18.

Lopez, S. H. (2007). Efficiency and the fix revisited: Informal relations and mock routinization in a nonprofit nursing home. Qualitative Sociology, 30(3), 225-247.

Marsland, D., Oakes, P., \& White, C. (2015). Abuse in care? A research project to identify early indicators of concern in residential and nursing homes for older people. The Journal of Adult Protection, 17(2), 111-125.

Montgomery, P., \& Bailey, P. H. (2007). Field notes and theoretical memos in grounded theory. Western Journal of Nursing Research, 29(1), 65-79.

Moore, S. (2018). Oops! Its happened again! Evidence of the continuing abuse of older people in care homes. The Journal of Adult Protection, 20(1), 33-46.

Parker, J., \& Crabtree, S. A. (2014). Covert research and adult protection and safeguarding: An ethical dilemma? The Journal of Adult Protection, 16(1), 29-40.

Pemberton, S. (2015). Harmful societies: Understanding social harm. Bristol: Policy Press.

Rees, C., \& Gatenby, M. (2014). Critical realism and ethnography. In P. K. Edwards, J. O’Mahoney, \& S. Vincent (Eds.), Studying organizations using critical realism: A practical guide (pp. 132-147). Oxford: Oxford University Press.

Scourfield, J. (2007). Are there reasons to be worried about the 'caretelization' of residential care? Critical Social Policy, 27(2), 155-180.

Scourfield, J. (2012). Caretelization revisited and the lessons of Southern Cross. Critical Social Policy, $32(1), 137-148$.

Spicker, P. (2011). Ethical covert research. Sociology, 45(1), 118-133.

Stevens, M., Biggs, S., Dixon, J., Tinker, A., \& Manthorpe, J. (2013). Interactional perspectives on the mistreatment of older and vulnerable people in long-term care settings. Sociology, 64(2), 267-286.

Sussex County Council. (2014). Orchid view serious case review. Sussex: West Sussex Adults Safeguarding Board.

Timmersmans, S., \& Almeling, R. (2009). Objectification, standardization, and commodification in health care: A conceptual readjustment. Social Science and Medicine, 69(1), 21-27.

Tombs, S. (2012). State-corporate symbiosis in the production of crime and harm. State Crime Journal, $1(2), 170-195$.

Tombs, S. (2016). Social protection after the crisis: Regulation without enforcement. Bristol: Policy Press.

Tombs, S., \& Whyte, D. (2007). Safety crimes. Cullompton, Devon: Willan.

Tombs, S., \& Whyte, D. (2010a). A deadly consensus: Worker safety and regulatory degradation under new labour. The British Journal of Criminology, 50(1), 46-65.

Tombs, S., \& Whyte, D. (2010b). The state and corporate crime. In R. Coleman, J. Sim, S. Tombs, \& D. Whyte (Eds.), State, power, crime (pp. 103-115). London: Sage. 
Tombs, S., \& Whyte, D. (2015). The corporate criminal. Why corporations must be abolished. Abingdon, Oxon: Routledge.

Whyte, D. (2014). Regimes of permission and state-corporate crime. State Crime Journal, 3(2), 237-246.

Yassi, A., \& Lockhart, K. (2013). Work-relatedness of low back pain in nursing personnel: A systematic review. International Journal of Occupational \& Environmental Health, 19(3), 223-244.

Publisher's Note Springer Nature remains neutral with regard to jurisdictional claims in published maps and institutional affiliations. 